\title{
GRAPHENE OXIDE AND METAL PARTICLES NANOCOMPOSITES FOR INHIBITION OF PATHOGENIC BACTERIA STRAINS
}

\author{
VIRGINIJA JANKAUSKAITE ${ }^{1}$, POVILAS LOZOVSKIS², VIRGILIJUS VALEIKA ${ }^{3}$, \\ ASTRA VITKAUSKIENE ${ }^{2}$ \\ ${ }^{1}$ Kaunas University of Technology, Faculty of Chemical Technologies, Kaunas, Lithuania, \\ Studentu St. 56, LT-51423 Kaunas, Lithuania, virginija.jankauskaite@ktu.lt \\ ${ }^{2}$ Lithuanian University of Health Science, Faculty of Medicine, Mickevičiaus St. 9 , \\ LT-44307 Kaunas,_ithuania, lozovskis@gmail.com, astravitka@hotmail.com \\ ${ }^{3}$ Kaunas University of Technology, Faculty of Chemical Technologies, Kaunas, Lithuania, \\ Radvilènu Av. 19, LT-51423 Kaunas, Lithuania, virgiijus.valeika@ktu.lt
}

\begin{abstract}
The most effective means to protect against bacterial invasion and to reduce the risk of dangerous infections are antibacterial components synthesis. Preliminary investigations show that hybrid coatings of graphene oxide doped with silver and copper nanoparticles have long-term bactericidal effect on a wide spectrum of standard bacterial strains. In this study the possibilities to use hybrid graphene oxide and metal nanoparticles composites for the inhibition not only standard bacteria, but also clinically important bacteria strains, which have developed multiple resistances to antibiotics, have been investigated. Resistant to antibiotics bacteria often cause dangerous infections in medical institutions of many countries due to the acquired resistance to many classes of antibiotics and the ability to obtain resistance to all antibiotics through mutations. Nanocomposite samples were characterized by TEM and SEM microscopy. The antibacterial activity was evaluated against gram-negative, gram-positive and clinical antibiotics resistant A. baumannii bacteria strains by solutions dilution method. The investigations demonstrated that hybrid nanocomposite shows synergistic mechanism of action and characterizes high efficiency against multidrug-resistant bacteria, such as A. baumannii bacteria strains decrease of viability.
\end{abstract}

Keywords: Graphene oxide and metal nanoparticle composites, multi-drug resistant bacteria, antibacterial activity

\section{INTRODUCTION}

The continuous increasing demand and use of antibiotics by population, in hospitals, and for veterinary purposes has led to accumulation of antibiotics in the environment. Continuous exposure of the bacterial fauna to even small concentrations of antibiotics or active metabolites could lead to the development of antibiotic resistant bacteria strains. The infections by these bacteria are causing health care systems tremendous amount of expenses. Therefore, the development of novel antibacterial agents looks promising in this context. For instance, silver $(\mathrm{Ag})$ nanoparticles are known to exhibit combinations of mechanisms (Singh et al., 2015), e.g. disruption of bacteria cell morphology, DNA condensation, inhibition of ribosome interaction, accumulation at lethal concentration in cell, protein denaturation, inhibition of DNA replication, depletion of adenosine triphosphate, modulation of cellular signaling, generation of reactive oxygen species, oxidative stress, etc. Copper $(\mathrm{Cu})$ nanoparticles are also proved to have bactericidal effect, the mechanisms of which may involve disruption of DNA helical structure through $\mathrm{Cu}$ ion cross-linking within and between nucleic acid strands and related mechanisms, which intervene cell biochemical processes (Kruk et al., 2015). Graphene and graphene oxide (GO) were also reported to exhibit bacterial toxicity effect, including cutting of intracellular metabolic routes, oxidative stress and rupture of cell membrane (Akhavan and Ghaderi, 2010). Therefore, the assembly of the mentioned 
nanoderivatives into nanocomposite materials was supposed to show enhanced bactericidal effect.

In this paper, ability of nanocomposite obtained by silver and copper nanoparticles precipitation on graphene oxide sheets to inhibit not only gram-negative and grampositive bacteria, but also antibiotic resistant bacteria strains, was investigated. The morphology and antibacterial activity of the hybrid nanocomposite was evaluated.

\section{EXPERIMENTAL}

\section{Materials}

Highly concentrated GO dispersion in water (concentration $-5 \mathrm{~g} / \mathrm{L}$; flake size 0.5-5 $\mu \mathrm{m}$ ) was obtained from Graphene Laboratories Inc. and used as received. Chemicals for nanoparticles synthesis were purchased from Sigma-Aldrich. The metal nanoparticles were synthesized by simple and cost-effective chemical reduction methods. The $\mathrm{Cu}$ nanoparticles colloidal solution $(\sim 2.5 \mathrm{mg} / \mathrm{L})$ was prepared using appropriate amount of copper(II) chloride dehydrate as precursor and L-ascorbic acid as reductor. High concentrated Ag NPs colloidal solution $(\sim 12 \mathrm{mg} / \mathrm{L})$ was prepared by new silver nitrate reduction with polyvinylpyrrolidone $(\mathrm{Mn}=10000)$ method. The graphene oxide doped with $\mathrm{Ag}$ and $\mathrm{Cu}$ nanoparticles $(\mathrm{GO}-\mathrm{Ag}-\mathrm{Cu})$ nanocomposite solutions were prepared by mixing highly concentrated $\mathrm{GO}$ dispersion with $\mathrm{Cu}$ and $\mathrm{Ag}$ nanoparticles colloidal solutions with 1:1:1 ratio, respectively. The corresponding thin nanocomposite films were assembled on the glass cover slips using same technique and technological parameters as described in (Lazauskas et al., 2014).

\section{Characterization}

TEM images were acquired on Tecnai G2 F20 X-TWIN (FEI) equipped with field emission electron gun with accelerating voltage of $200 \mathrm{kV}$. Elemental analysis was performed using an energy dispersive X-ray (EDX) spectrometer. Samples were prepared for TEM by diluting colloidal solutions of nanocomposites in ethanol and placing a drop of solution on a Lacey carbon grid and left overnight at $21{ }^{\circ} \mathrm{C}$.

SEM micrographs were acquired using field emission scanning electron microscope Quanta 200 FEG (FEI) and e-line plus multi-application nanoengineering workstation (Raith).

\section{Antibacterial Activity Measurement}

The antibacterial activity of hybrid $\mathrm{GO}-\mathrm{Cu}-\mathrm{Ag}$ nanocomposite was evaluated against gram-negative Escherichia coli (E. coli) (ATCC 25922), Pseudomonas aeruginosa (P. aeruginosa) (ATCC 27853), Klebsiella pneumoniae (K. pneumoniae) (ATCC 700603), which developed resistance to $\beta$-lactams, fluoroquinolones and aminoglycosides, and gram-positive Staphylococcus aureus (S. aureus) (ATCC 25923) and methicillin-resistant Staphylococcus aureus (MRSA), which are resistant to $\beta$ lactams, fluoroquinolones and macrolides, bacteria strains. Additionally, for investigations 79 clinical Acinetobacter baumannii (A. baumannii) strains have been separated from the various clinical materials in microbiology laboratory using standard procedures. Standard bacteria were cultured in Tryptone Soya Broth (TSB) solution (30 $\mathrm{g} / \mathrm{L}$ ). Bacteria were first cultured in a tube with $30 \mathrm{~mL}$ of TSB. The incubation was 
performed at $37^{\circ} \mathrm{C}$ and oscillated at a frequency of $150 \mathrm{rpm}$ for $24 \mathrm{~h}$ to obtain the overnight phase of the bacteria. Following that, about $1 \mathrm{~mL}$ amount of the bacteria were pipetted from the overnight phase into another tube with freshly prepared $30 \mathrm{~mL}$ of TSB, respectively. Bacteria were grown at $37^{\circ} \mathrm{C}$ in the incubator shaker for another $5 \mathrm{~h}$ to obtain the bacteria with higher activity. The stationary phase bacteria were diluted to concentration ca. $103 \mathrm{CFU} / \mathrm{mL}$ with $\mathrm{NaCl}$ solution $(0.85 \%)$ and mixed with $\mathrm{GO}$ and nanoparticles colloidal solution with 1:1 ratio. Afterwards, the samples were taken and placed on Petri dishes surface, and incubated at $37{ }^{\circ} \mathrm{C}$ for $24 \mathrm{~h}$. Bacteria survival was recorded over a $6 \mathrm{~h}$ period.

Antibiotic resistant $A$. baumannii strains were cultivated overnight on $5 \%$ blood agar (BD, USA) at temperature of $37^{\circ} \mathrm{C}$. Saline was used to make $A$. baumannii inoculate of concentration of $0.5 \mathrm{MF}$. One part of inoculate was mixed with 9 parts of $\mathrm{GO}-\mathrm{Cu}-\mathrm{Ag}$ nanocomposite colloidal solution. The sample was mixed by pipetting and placed at $37^{\circ} \mathrm{C}$ for incubation of $1 \mathrm{~h}$ and $2 \mathrm{~h}$. Incubated mix was spread on $5 \%$ blood agar plate with $1 \mu 1$ loop and then cultivated $24 \mathrm{~h}$ at $37^{\circ} \mathrm{C}$. The bacterial growth was evaluated next day using mass spectroscopy method for determination of bacteria species.

\section{RESULTS AND DISCUSSIONS}

\section{Morphology of GO-Ag-Cu Nanocomposite}

At first, the morphology of hybrid nanocomposite was evaluated. TEM image of $\mathrm{GO}-\mathrm{Cu}-\mathrm{Ag}$ nanocomposite is shown in Figure $1 \mathrm{a}$ and $\mathrm{1b}$. It clearly illustrates that $\mathrm{Ag}$ and $\mathrm{Cu}$ nanoparticles are precipitated on $\mathrm{GO}$ sheets. The nanoparticles are well dispersed across the GO surface with relatively low density of assembled aggregates. In order to quantify the nanoparticle presence, EDX point analysis on the GO wrinkle with high concentration of nanoparticles was performed (Figure 1b). The EDX spectrum confirms the presence of $\mathrm{Ag}$ and $\mathrm{Cu}$ nanoparticles on $\mathrm{GO}$ nanosheet surface. Fig. 1c shows SEM image of GO multilayer film assembled on glass coverslip surface using vertical dip-coating technique. The GO multilayer film was found to be uniform with a dense distribution of microscopic wrinkles on its surface. It is known that GO nanosheets may tend to yield wrinkled assemblies due to the solution phase properties, such as $\mathrm{pH}$, and, thus, are solution phase property dependent. Addition of $\mathrm{Ag}$ and $\mathrm{Cu}$ nanoparticles colloid solutions disrupt GO sheets and sharp edges of GO are formed (Fig. 1d). It is reported that sharp edges of sheets could cut through the bacterium's cell membrane causing intracellular matrix to leak, eventually leading to the GO toxicity mechanism. As can be seen from Figure 1d, the nanocomposite exhibits $\mathrm{Ag}$ and $\mathrm{Cu}$ nanoparticles decorated GO sheets. Figure 1e shows killed E. coli bacteria strains after contact with GO-Cu-Ag nanocomposite as a bactericidal agent. In some cases were found that bacteria are microencapsulated with GO sheets (Figure 1f).

\section{Antibacterial Activity of Hybrid Nanocomposite}

Figure 2 shows survival curves of gram-negative and gram-positive bacteria strains during $6 \mathrm{~h}$ period after contact with $\mathrm{GO}-\mathrm{Cu}-\mathrm{Ag}$ nanocomposite as a bactericidal agent. GO-Cu-Ag nanocomposite markedly affected S. aureus, E. coli, K. pneumoniae and $P$. aeruginosa cellular viability during $3 \mathrm{~h}$ period of incubation. Though MRSA showed higher resistance, but this bacterium did not survive $6 \mathrm{~h}$ period. It is a good indication that synergistic effect of applied nanoderivatives with multiple toxicity mechanisms 
(due to the morphological diversity) has stronger bactericidal effect. Based on obtained results, the predicted bacterium inactivation mechanism via interaction with GO-Cu-Ag nanocomposite was devised (Jankauskaite et al., 2016).
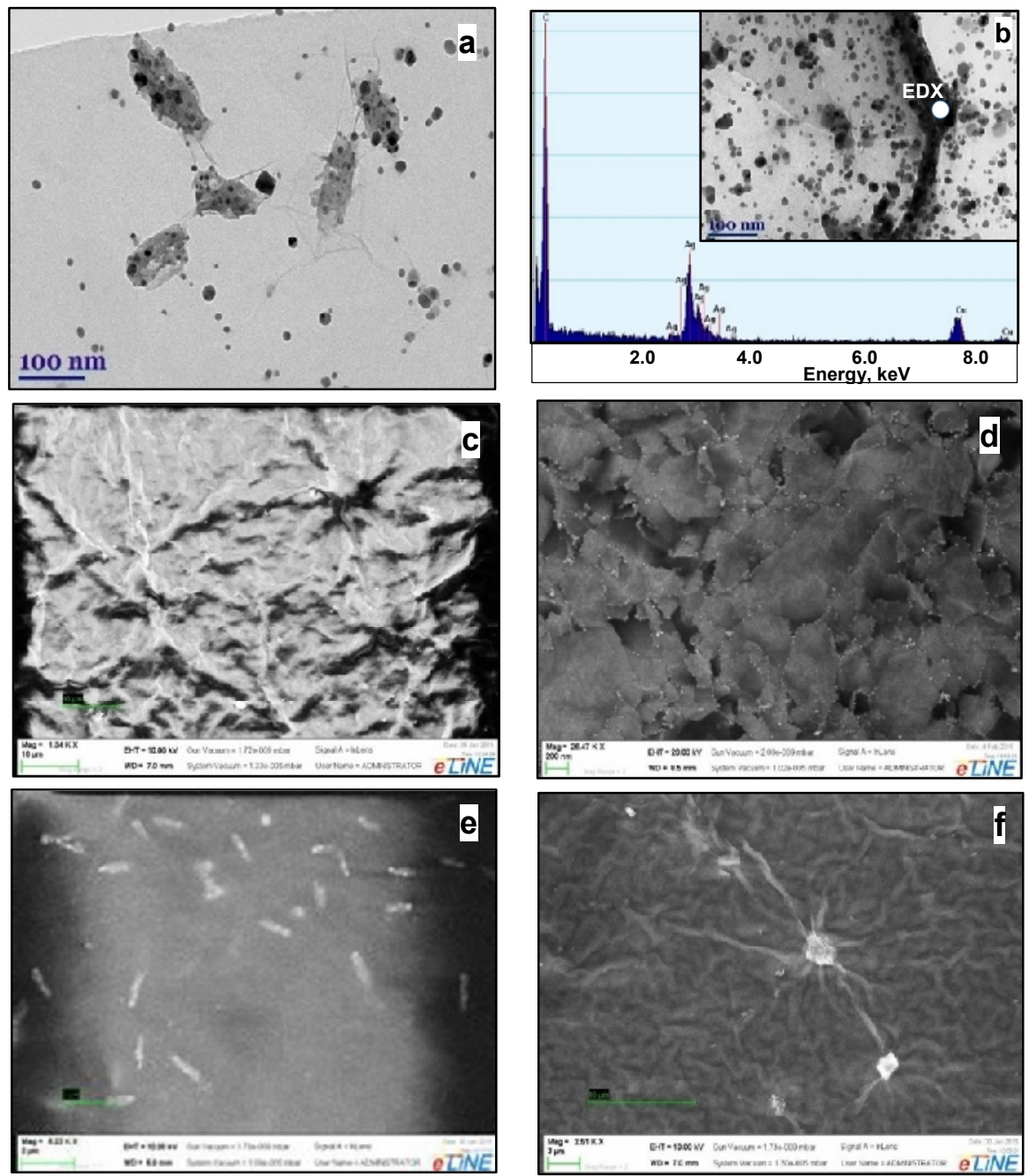

Figure 1. Hybrid GO-Cu-Ag nanocomposite TEM image (a) and EDX spectrum (b); SEM images of GO nanosheet (c) and GO-Cu-Ag nanocomposite (d), E. coli bacteria killed after interaction with nanocomposite (e), bacteria microencapsulated with GO sheets (f)

The positively charged $\mathrm{Cu}$ and $\mathrm{Ag}$ nanoparticles mainly adsorb on the negatively charged GO nanosheet surface (Figure 1a). Thus, it is expected that $\mathrm{Cu}$ and $\mathrm{Ag}$ nanoparticles are able to interact with entire bacterium's surface. This is specifically 
relevant in regard to the effect that nanoparticles had on gram-negative bacteria (E. coli, $P$. aeruginosa, and K. pneumonia), which have a larger surface area compared to grampositive bacteria represented by $S$. aureus and MRSA, which are more spherical and have less surface area. Furthermore, MRSA resistance to $\mathrm{Cu}$ and $\mathrm{Ag}$ nanoparticles could be the product of a decreased cross-linking of peptidoglycan strands which leads to the exposure of more D-Ala-D-Ala residues resulting in areas of bind and trap for nanoparticles. It is predicted that the nanoparticle interactions with bacterial cell membrane are mainly caused by to electrostatic attraction, which increases the membrane permeability eventually leading to rupture and leakage of intracellular component, resulting in cell's death. It is also possible that nanoparticles interaction with cell membrane could also cause the deterioration of the energy metabolism by interfering with the electron transport (respiratory) chains. The gram-negative bacteria were more susceptible to nanoparticles which can be explained in part by the difference in the presence of peptidoglycans present in S. aureus. Relative resistance of MRSA is also possibly explained by the fact that this bacterium has a much thicker cell wall which is partially responsible for their resistance to vancomycin. Finally, another potential mechanism of the GO sheets on gram-negative bacteria such as E. coli and $P$. aeruginosa is damage of the flagellum, a vital organelle that confers virulence to these bacteria. This can result in bactericidal properties and immobilization of bacteria. Furthermore, the enfolded GO sheet fragments with sharp edges could instantly cut through the bacterium's cell membrane upon contact. This ability increases with addition of nanoparticles colloidal solutions that influences on the fragmentation of GO nanosheets.

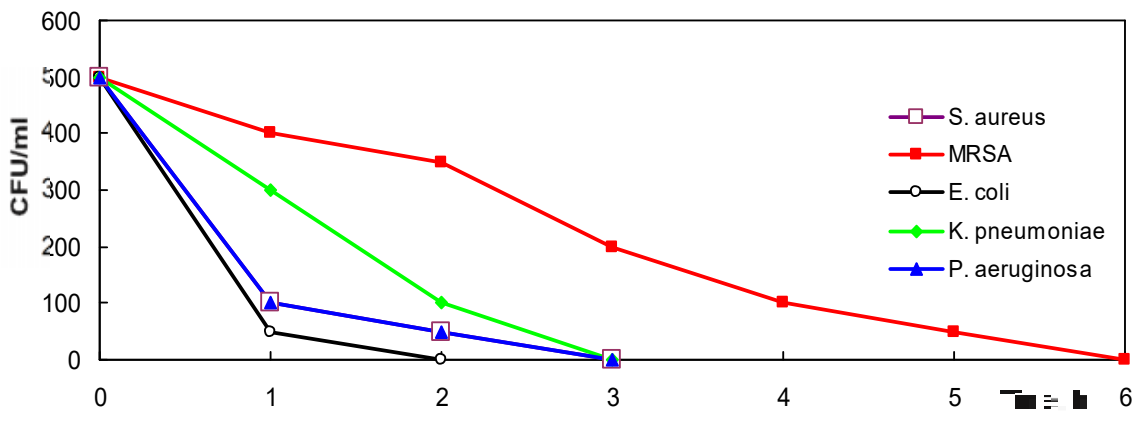

Figure 2. Survival curves of different bacteria strains during $6 \mathrm{~h}$ period with $\mathrm{GO}-\mathrm{Cu}-$ Ag nanocomposite

Thus, the morphological diversity of nanoparticles and GO construct the synergistic bactericidal effect (Figure 2), which is found to be more effective than individual nanoderivatives.

Thus, it is important to consider the use of $\mathrm{GO}-\mathrm{Ag}-\mathrm{Cu}$ nanocomposite in the applications that require materials with high antibacterial effectiveness. Therefore, the influence of $\mathrm{GO}-\mathrm{Ag}-\mathrm{Cu}$ nanocomposites on the antibiotic resistant bacterium strains was evaluated. Generally, A. baumannii strains have acquired resistance mechanisms for the most of tested antibiotics (Afzal-Shah et al., 2001). It was found that $22.8 \%$ of strains were resistant to all tested antibiotics. As can be seen from Table 1, after $1 \mathrm{~h}$ of incubation $\mathrm{GO}-\mathrm{Ag}-\mathrm{Cu}$ nanocomposite showed better performance on strains that were 
susceptible, than resistant to ceftazidime, and ciprofloxacin, doxycycline, carbapenems (imipenem and meropenem), gentamicin, tigecycline.

Table 1. Effect of hybrid $\mathrm{GO}-\mathrm{Cu}-\mathrm{Ag}$ nanocomposite on multi-drug resistant A. baumannii strains

\begin{tabular}{lcccc}
\hline & \multicolumn{2}{c}{ Susceptible to antibiotics } & \multicolumn{2}{c}{ Resistant to antibiotics } \\
& $1 \mathrm{~h}$ & $2 \mathrm{~h}$ & $1 \mathrm{~h}$ & $2 \mathrm{~h}$ \\
\hline Ceftazidime & 100.0 & 66.7 & 37.0 & 76.7 \\
Ciprofloxacin & 100.0 & 83.3 & 37.0 & 75.3 \\
Carbapenem & 77.8 & 77.8 & 37.1 & 75.7 \\
Doxycycline & 57.6 & 51.5 & 30.4 & 93.5 \\
Gentamicin & 69.2 & 92.3 & 36.4 & 72.7 \\
Amikacin & 56.2 & 93.8 & 61.9 & 71.4 \\
Tigecycline & 63.3 & 80.0 & 34.7 & 73.5 \\
\hline
\end{tabular}

After $2 \mathrm{~h}$ of incubation $\mathrm{GO}-\mathrm{Ag}-\mathrm{Cu}$ nanocomposites effect on strains that were resistant and susceptible to antibiotics became similar. On the other hand, some of effected A. baumannii strains showed recovery after $2 \mathrm{~h}$ of incubation.

\section{CONCLUSIONS}

$\mathrm{Cu}$ and $\mathrm{Ag}$ nanoparticles precipitated on $\mathrm{GO}$ sheets is markedly effective bactericidal agent against wide range of gram-negative and gram-positive bacteria strains due to the possible synergy of the multiple toxicity mechanisms. A systematic morphology analysis of the corresponding nanoderivatives was performed employing SEM and TEM and provided guideline information for addressing toxicity mechanisms.

$\mathrm{GO}-\mathrm{Cu}-\mathrm{Ag}$ nanocomposite also show significant effect on antibiotic resistant A. baumannii strains that are susceptible to $\beta$-lactams (ceftazidime, carbapenems) and ciprofloxacin after a short exposition, but it is needed longer incubation time to effect resistant A. baumannii strains. $\mathrm{GO}-\mathrm{Cu}-\mathrm{Ag}$ nanocomposite inhibits growth of aminoglycoside (gentamicin, amikacin) and tygecycline susceptible strains as well as resistant after $2 \mathrm{~h}$ of exposition.

\section{REFERENCES}

Afzal-Shah, M., Woodford, N. and Livermore, D.M. (2001), "Characterization of OXA-25, OXA-26, and OXA-27, molecular class D beta-lactamases associated with carbapenem resistance in clinical isolates of Acinetobacter baumannii”, Antimicrobial Agents and Chemotherapy, 45(2), 583-588, https://doi.org/10.1128/AAC.45.2.583-588.2001.

Akhavan, O. and Ghaderi, E. (2010), "Toxicity of graphene and graphene oxide nanowalls against bacteria", ACS Nano, 4(10), 5731-5736, https://doi.org/10.1021/nn101390x.

Jankauskaitè, V. et al. (2016), "Bactericidal effect of graphene oxide/Cu/Ag nanoderivatives against Escherichia coli, Pseudomonas aeruginosa, Klebsiella pneumoniae, Staphylococcus aureus and Methicillin-resistant Staphylococcus aureus", International Journal of Pharmaceutics, 511(1), 90-97, https://doi.org/10.1016/j.ijpharm.2016.06.121.

Kruk, T. et al. (2015), "Synthesis and antimicrobial activity of monodisperse copper nanoparticles", Colloids Surface B, 128, 17-22, https://doi.org/10.1016/j.colsurfb.2015.02.009.

Lazauskas, A. et al. (2014), "Thermally-driven structural changes of graphene oxide multilayer films deposited on glass substrate", Superlattices and Microstructures, 75, 461-467, https://doi.org/10.1016/j.spmi.2014.08.006.

Singh, R. et al. (2015), "Bacteriagenic silver nanoparticles: synthesis, mechanism, and applications", Applied Microbiology and Biotechnology, 99(11), 4579-4593, https://doi.org/10.1007/s00253-015-6622-1. 